\title{
The Goals of Financial Research in the Twenty-First Century
}

\section{Jeffrey Jarrett*}

Professor, Department of Management Science, University of Rhode Island, USA

Financial modeling in recent years erred greatly in predicting the results for the inefficient and inaccurate models designed to estimate and predict the financial risks associated with newly developed financial instruments. There are so many of these financial instruments today designed to satisfy the appetite of an extremely wide variety of investors with widely varying goals. Standard statistics coupled with financial instruments designed to ignore and not even consider all the complexities of investing were a significant cause of the financial collapse in 2007-2008. Regulation of the financial instruments often referred to as "swaps" and "derivatives" with values based on averages were misunderstood by inept buyers and sellers. Hence, a goal of modern finance to extend and explore our knowledge of financial markets and their associated decision making contains elements which increase our knowledge of economic events. Social good is produced when we understand financial decision making better. Hence, the subject of modern financial analysis is valuable to those beyond the field of finance and includes the related methods discussed in operations research, business and economic statistics and applied mathematics in decision modeling.

The purpose of this special issue provides a method or outlet for discussion of the very important problems associated with financial markets in the domestic economy and its interrelationship with other economies around the globe. Financial markets are associated with each other but not always in the same way nor are the relationships necessarily on an even plain. The role of regulation in this area is quite well founded. Regulation has the goal of achieving an equal opportunity for all investors and consumers. The special needs of those that are economically impaired by archaic laws and ideas about free markets must be addressed. This often includes the methods by which address of the problems associated with imperfect law and its application. The days of "laissez-faire" never really existed and it is only with mixed capitalistic system that we have in Western democracies can we achieve something close to equal opportunity for all.

We study how markets behave and respond to stimuli from governments, economic actions and polices initiated abroad and most importantly consumer spending. The purpose is to improve the promulgation and interpretation of law to make the markets more competitive and less imperfect. In other fields, we have seen how the lack of regulation and transparency results in a chaotic market. For example, gun control in the United States is one area where law is totally imperfect leading to chaotic and socially undesirable results. Laws designed to protect Americans rights to hunt and protect their rights have produced abnormal and dangerous results with loss of human life and the destruction of rights of Americans to live in a fee and protected environment.

By studying financial markets, financial modeling and decisiontheoretic models, we can learn to enact legislation to correct the abuses that led to financial disasters. By writing more perfect law, we protect the environment of investment, finance and opportunity from being polluted by the effects of socially undesirable outcomes designed to increase the wealth of a minority and the expense of the majority who may not have equal amounts of economic power.

We welcome the submission of studies of financial markets, business and financial decision making and related subjects with the notion that we are to improve the economies of all. The outcome of the research should benefit the decision makers but we should understand that the outcomes should not lead to undesirable results or results that affect some disenfranchised group severely. What laws and regulations are necessary to eliminate the deaths of many impoverished workers in Bangladesh who had little or no chance to escape with their lives from a fire and working conditions similar to that of the "Triangle Waistcoat Factory" in lower Manhattan of a century ago? [1]

Stated differently, we must learn from studies of the past to prevent future dislocations, imperfect financial markets and regulations to benefit the few at the expense of most others. The economic system if operating properly will permit ease of entry and exit from markets, transparency of financial statements, financial instruments that can be understood by all consumers. Studies of business and financial analysis will enable those parties involved to speak with educated voice to seek change for the betterment of all.

We welcome research because we feel society gains by knowledge even when the opposition to modern understanding is stubborn and often foreboding [Jeffrey E. Jarrett, PhD].

\section{References:}

1. (1911) "Complete Transcript of Triangle Fire". Cornell University ILR Schoo Digital Commons @ILR 2: 22.
*Corresponding author: Jeffrey Jarrett, Professor, Department of Management Science, University of Rhode Island, USA, Tel: 1-401-874-4169; Fax: 1-401-874 4312; E-mail: jejarrett@mail.uri.edu

Received November 29, 2012; Accepted November 29, 2012; Published December 05, 2012

Citation: Jarrett $\mathrm{J}$ (2012) The Goals of Financial Research in the Twenty-First Century. J Bus \& Fin Aff 1:e120. doi:10.4172/2167-0234.1000e120

Copyright: (C 2012 Jarrett $\mathrm{J}$. This is an open-access article distributed under the terms of the Creative Commons Attribution License, which permits unrestricted use, distribution, and reproduction in any medium, provided the original author and source are credited. 